\title{
Synthesis, crystal structure and larvicidal activity of novel diamide derivatives against Culex pipiens
}

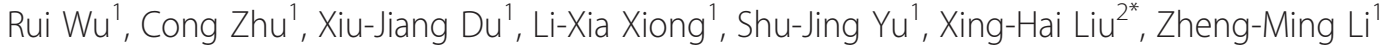 \\ and Wei-Guang Zhao ${ }^{1 *}$
}

\begin{abstract}
Background: Culex is an important mosquito as vectors for the transmission of serious diseases, such as filariasis, West Nile virus, dengue, yellow fever, chikungunya and other encephalitides. Nearly one billion people in the developing countries are at risk. In order to discover new bioactive molecules and pesticides acting on mosquito, we designed active amide structure and synthesized a series of novel diamide derivatives.

Results: A series of novel diamide derivatives were designed and synthesized. Their structures were characterized by ${ }^{1} \mathrm{H}$ NMR, FTIR and HRMS. The single crystal structure of compound $6 \mathrm{n}$ was determined to further elucidate the structure. Biological activities of these compounds were tested. Most of them exhibited higher mosquito larvicidal activity. Especially compound $6 \mathrm{r}$ displayed relatively good activity to reach $70 \%$ at $2 \mu \mathrm{g} / \mathrm{mL}$.
\end{abstract}

Conclusion: A practical synthetic route to amide derivatives by the reaction of amide with another acid is presented. This study suggests that the diamide derivatives exhibited good effective against mosquito.

Keywords: Mosquito larvicidal activity, Diamide derivatives, Crystal structure, Synthesis

\section{Background}

Culex is an important mosquito as vectors for the transmission of serious diseases [1,2], such as filariasis, West Nile virus, dengue, yellow fever, chikungunya and other encephalitides. Lymphatic filariasis, which may be caused by different species of filarial worm, e.g., Wuchereria bancrofti, has a scattered distribution in the tropics and subtropics [3]. Nearly one billion people in the developing countries are at risk. Culex pipiens $L$. is the most commonly occurring mosquito pest in urban and suburban areas [4], which is mainly the intermediate host and vector of Bancroftian filariasis.

According to World Health Organisation (WHO), the one of strategies is to destroy their vectors or intermediate hosts. The best method is control of mosquito larvae using insecticides [5-7], such as organo-phosphates, natural products and heterocycles types. It is an urgent need to develop new insecticides which are more environmentally safe and also biodegradable and target specific against mosquitoes.

\footnotetext{
* Correspondence: xhliu@zjut.edu.cn; zwg@nankai.edu.cn

${ }^{2}$ College of Chemical Engineering \& Materials Sciences, Zhejiang University of Technology, Hangzhou 310014, China

'State Key Laboratory of Elemento-Organic Chemistry, National Pesticide Engineering Research Center (Tianjin), Nankai University, Tianjin 300071, China
}

Amide derivatives have become one of the focuses in the development of pesticides because of their high biological activities, such as fungicidal activities [8-11], herbicidal activities [12-15], insecticidal activities [16,17], anticancer activity $[18,19]$, antibacterial activity [20] and so on. In line with our continueous efforts to synthesize bioactive lead compounds, the title compounds were designed by introducing amide pharmacophore into the valine scaffold. Thus, guaiacol was used as start materials, 22 novel diamides were synthesized. All the compounds were unequivocally characterized by NMR, IR, HRMS. The single crystal structure of compound $6 \mathrm{n}$ was determined to further elucidate the structure. The biological activities of title compounds against Culex pipiens were determined, the results showed that most of the synthesized compounds exhibited antibacterial activity against Culex pipiens, compounds $6 \mathrm{n}$ showed good activity against Culex pipiens at $2 \mu \mathrm{g} / \mathrm{mL}$.

\section{Results and discussion}

\section{Synthesis and spectra}

The synthetic route to the title compounds is outlined in Scheme 1 [see Additional file 1]. Compound 3 was synthesized at the condition of neutral. When the 2-oxoacetic 


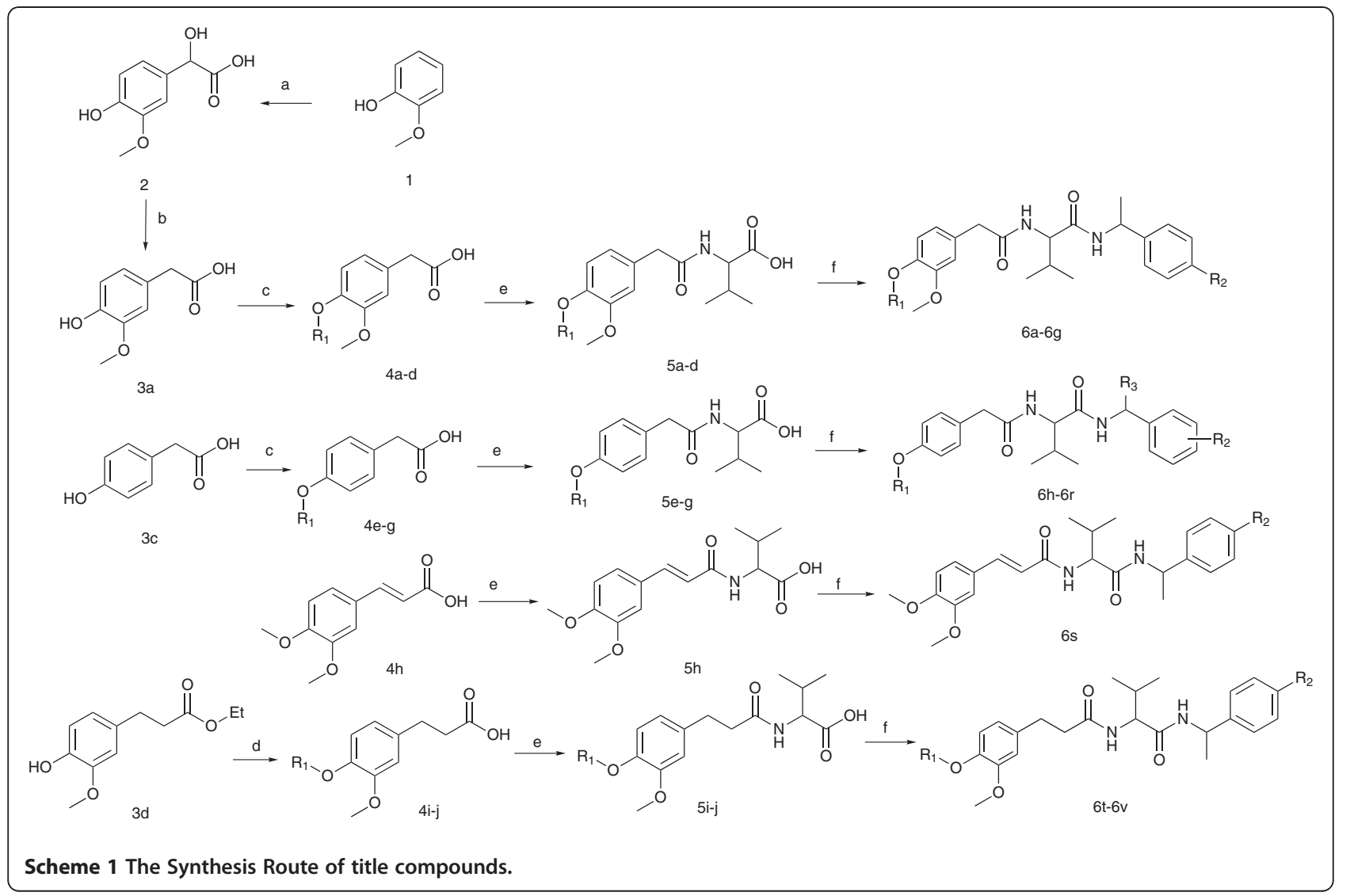

acid was drop wised to the start material 2-methoxyphenol, the $\mathrm{pH}$ of the mixture increase, while it must be reacted under $\mathrm{pH}=7$, as higher $\mathrm{pH}$ decreased the yield of product. So a solution of $\mathrm{NaOH}$ should be drop wised at the same time. Several procedures are available for the synthesis of amide derivatives. Due to the dissolve of valine in the organic solvent, such as THF, so it can not react with the 2phenylacetyl chloride. In this paper, the 2-phenylacetyl chloride was reacted with the solution of sodium 2-amino3-methylbutanoate in water.

The structures of all new compounds were confirmed by their spectra $\left({ }^{1} \mathrm{H}\right.$ NMR and FTIR) data. Additional file shows the structures, yields and HRMS data for title compounds in more detail [see Additional file 2]. The proton magnetic resonance spectra of the amides have been recorded in $\mathrm{CDCl}_{3}$. The $\mathrm{COOH}$ of amide intermediates 4 is not determined. All the title compounds of HRMS are $\mathrm{M}+\mathrm{H}$, or $\mathrm{M}+\mathrm{Na}$ peak.

\section{Crystal structure}

The structure of compound 6n was further confirmed by single crystal X-ray diffraction analysis (Figure 1). Generally, the average bond lengths and bond angles of phenyl ring and amide bond are normal ranges. The $\mathrm{C} 8-\mathrm{N} 1$ and C13-N2 bond [1.337(2) $\AA$ and 1.334(2) $\AA]$ is shorter than a normal C-N single bond (1.47 $\AA$ ), which shows that C8-
$\mathrm{N} 1$ and $\mathrm{C} 13-\mathrm{N} 2$ is conjugated with the $\mathrm{O} 1-\mathrm{C} 8$ and $\mathrm{O} 2-$ $\mathrm{C} 13$ double bond respectively. The sum of the $\mathrm{C}-\mathrm{N}-\mathrm{C}$ angles around the $\mathrm{N}$ atom is $122^{\circ}$ which means in the solid state there is no $\mathrm{p}-\pi$ conjugation between the benzyl group and the $\mathrm{N}$ atom. In the molecular structure of compound 6n, acyl group is planar with amide group and the torsional angles of O1-C8-N1-H1 and O2-C13$\mathrm{N} 2-\mathrm{H} 2$ is $178.68^{\circ}$ and $177.06^{\circ}$. The C1-C6 and C15-C20 phenyl rings are fairly planar with plane equation $5.176 \mathrm{x}+$ $3.771 y-6.693 z=2.7161$ and $9.008 x+4.192 y-0.151 z=$ 3.0785 , the mean deviation from the plane is 0.0026 and $0.0070 \AA$ respectively. In the molecular structure of title compound, the $\theta$ angle of the two benzene rings is $39.7^{\circ}$, and the distance is $10.68 \AA$ between the two rings. Moreover, intermolecular N1-H1-O2 hydrogen bonds are also observed in the crystal structure. The title compound has an extensive one dimension chain polymer of hydrogen bonding involving the atoms, $\mathrm{N}$ and $\mathrm{O}$. In the $b c$ plane, they are linked together by N1-H1-O2 hydrogen bonds. This hydrogen-bonding sequence is repeated to form a ring. The ring is shaped like a decagon and has two $\mathrm{O} 1$ atoms at the vertices, leading to a hydrogen-bond network defining cyclic motifs denoted $R_{2}^{2}(10)$. The vertices are shared with neighboring decagon to form an infinite two-dimensional network of hydrogen bonds in the $b c$ plane. 


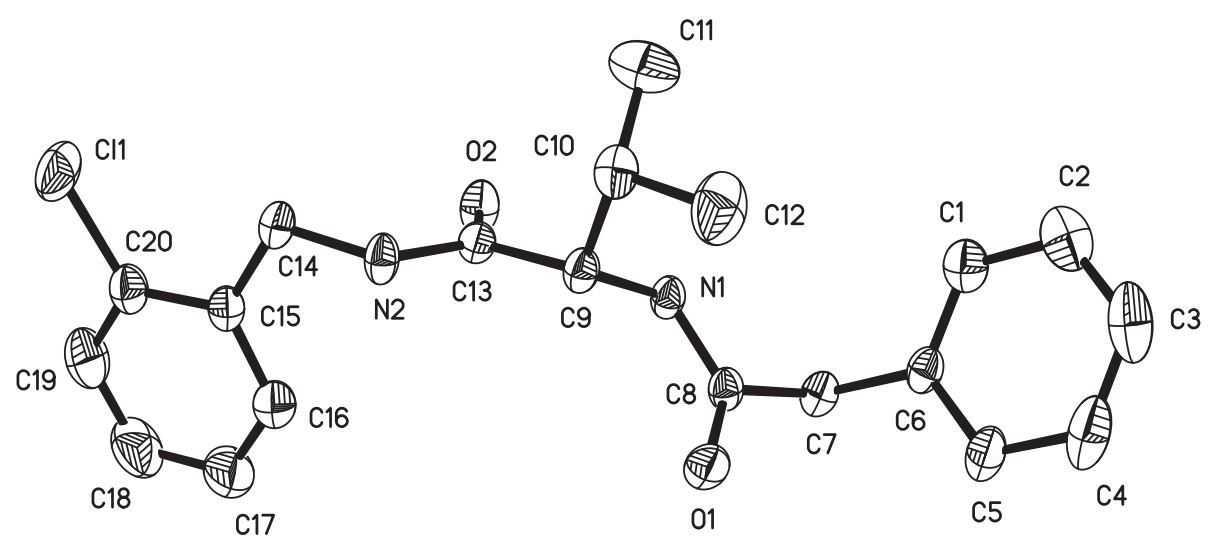

Figure 1 The crystal structure of compound $6 n$.

\section{Larvicidal activity against mosquito}

The toxicity of test compounds to Culex pipiens pallens larvae is listed in Table 1 . The results indicated that most of the title compounds exhibited excellent activities against mosquito at $5 \mu \mathrm{g} / \mathrm{mL}$. For example, the larvicidal activities of compounds $6 \mathrm{~b}, 6 \mathrm{~m}, 6 \mathrm{p}, 6 \mathrm{r}$ and $6 \mathrm{t}$ against mosquito at $5 \mu \mathrm{g} / \mathrm{mL}$ are $70 \%, 80 \%, 70 \%, 100 \%$ and $70 \%$, respectively. Especially, compound 6r still maintain high insecticidal activity (70\%), even at $2 \mu \mathrm{g} / \mathrm{mL}$. All the title compounds exhibited moderate larvacidal activities against mosquito, except compound $6 \mathbf{j}$.

\section{Experimental \\ Chemistry}

Melting points were determined by an X-4 apparatus and uncorrected. ${ }^{1} \mathrm{H}$ NMR spectra were measured on a Bruker AV-400 instrument using TMS as an internal standard and DMSO- $d_{6}$ as the solvent. HRMS data was obtained on a FTICR-MS instrument (Ionspec 7.0 T). Crystallographic data of the compound were collected on a rigaku saturn diffractometer. Microwave activation

Table 1 Larvicidal activity against Mosquito of title compounds at $5 \boldsymbol{\mu g} / \mathrm{mL}$

\begin{tabular}{cccc}
\hline No. & Death rate (\%) & No. & Death rate (\%) \\
\hline $\mathbf{6 a}$ & 50 & $\mathbf{6 ~ I ~}$ & 50 \\
$\mathbf{6 b}$ & 70 & $\mathbf{6 ~} \mathbf{~}$ & 80 \\
$\mathbf{6 c}$ & 50 & $\mathbf{6 n}$ & 50 \\
$\mathbf{6 d}$ & 53 & $\mathbf{6 0}$ & 50 \\
$\mathbf{6 e}$ & 53 & $\mathbf{6 p}$ & 70 \\
$\mathbf{6 f}$ & 50 & $\mathbf{5 q}$ & 60 \\
$\mathbf{6} \mathbf{g}$ & 43 & $\mathbf{6 r}$ & 100 \\
$\mathbf{6} \mathbf{h}$ & 54 & $\mathbf{6} \mathbf{s}$ & 50 \\
$\mathbf{6 i}$ & 60 & $\mathbf{6 ~ t}$ & 70 \\
$\mathbf{6 j}$ & 30 & $\mathbf{6 u}$ & 43 \\
$\mathbf{6} \mathbf{k}$ & 50 & $\mathbf{6 v}$ & 67 \\
\hline
\end{tabular}

was carried out with CEM Discover ${ }^{\mathrm{TM}}$ focused microwave $(2450 \mathrm{MHz}, 300 \mathrm{~W})$. All the reagents are of analytical grade or freshly prepared before use. The course of the reactions was monitored by TLC; analytical TLC was performed on silica gel GF 254. Intermediates 2, 3, 4 and 5 were prepared according to the reported methods [21-29] and used without further purifications, the process for preparing of them can be found in Additional file 2.

\section{Crystal structure}

The crystal of compound $6 \mathrm{n}$ with dimensions of $0.20 \mathrm{~mm} \times 0.18 \mathrm{~mm} \times 0.14 \mathrm{~mm}$ was mounted on a Rigaku Saturn CCD area-detector diffractometer with a graphitemonochromated MoK $\alpha$ radiation $(\lambda=0.71073 \AA$ ) by using a phi and scan modes at 293(2) $K$ in the range of $2.55^{\circ} \leq \theta \leq 27.85^{\circ}$. The crystal belongs to Triclinic system with space group $\mathrm{P}-1$ and crystal parameters of $\mathrm{a}=9.4583$ (19) $\AA, b=10.494(2) \AA, c=11.545(2) \AA, \alpha=70.49(3)^{\circ}, \beta=$ 73.27(3) ${ }^{\circ}, \gamma=64.00(3)^{\circ}, V=957.2(3) \mathrm{A}^{3}, \mathrm{Dc}=1.245 \mathrm{~g} / \mathrm{cm}^{3}$. The absorption coefficient $\mu=0.0815 \mathrm{~mm}^{-1}$ and $\mathrm{Z}=2$. The structure was solved by direct methods with SHELXS-97 and refined by the full-matrix least squares method on $\mathrm{F}^{2}$ data using SHELXL-97 [30]. The empirical absorption corrections were applied to all intensity data. $\mathrm{H}$ atom of $\mathrm{N}-\mathrm{H}$ was initially located in a difference Fourier map and were refined with the restraint $\operatorname{Uiso}(\mathrm{H})=1.2 \mathrm{Ueq}$ $(\mathrm{N})$. Other $\mathrm{H}$ atoms were positioned geometrically and refined using a riding model, with $\mathrm{d}(\mathrm{C}-\mathrm{H})=0.93-0.97 \AA$ and $\operatorname{Uiso}(\mathrm{H})=1.2 \mathrm{Ueq}(\mathrm{C})$ or $1.5 \mathrm{Ueq}($ Cmethyl $)$. The final full-matrix least squares refinement gave $\mathrm{R}=0.0476$ and $w R^{2}=0.0971$.

\section{Larvicidal activity against mosquito}

A stock solution of each compound was prepared at $1000 \mu \mathrm{g} / \mathrm{mL}$ using acetone as a solvent. Each compound in acetone was suspended in distilled water with Tween$80(0.001 \%)$. Distilled water mixed with Tween-80 was 
used as control. Batches of 10 fourth-stage larvae of C. pipiens pallens were separately put into Beakers $(100 \mathrm{~mL})$ containing each test solution $(40 \mathrm{~mL})$ using a pipet. Each test compound was evaluated at the level of $2 \mu \mathrm{g} / \mathrm{mL}$ in distilled water. Observation on larval mortality was recorded after $24 \mathrm{~h}$. The larvae were considered dead if appendages did not move when prodded with a needle. The experimental results are summarized in Table 1.

$$
\text { Rectified mortality }(\%)=(\mathrm{A} 1-\mathrm{A} 2) /(100-\mathrm{A} 2) \times 100
$$

where the $\mathrm{Al}(\%)$ is the mortality in treatment group, and the A2 (\%) is the mortality in control group.

\section{Conclusion}

In summary, a novel series of diamide derivatives were designed and synthesized. The synthesized compounds were characterized by spectral data $\left({ }^{1}\right.$ H NMR $)$ and HRMS (ESI). All of the compounds were subjected to larvicidal activity against mosquito. The results indicated that the synthesized compounds possessed good larvicidal activity against mosquito. Further studies are currently underway to optimize to enhance the larvicidal activity of the diamide derivatives.

\section{Additional files}

\section{Additional file 1: Supporting information}

Additional file 2: Contains the CIF for compound 1.

\section{Competing interests}

The authors declare that they have no competing interests.

\section{Authors' contributions}

The current study is an outcome of constructive discussion with $\mathrm{XHL}, \mathrm{ZML}$ and WGZ who offered necessary guidance to RW and RW to carry out their synthesis and characterization experiments. XHL were also involved in the drafting of the manuscript. LXX and SJY performed the biological activity tests; RW, CZ, XJD carried out the ${ }^{1} H$ NMR and HRMS, XHL elucidate the single crystal. WGZ were involved in revising the manuscript. All authors read and approved the final manuscript

\section{Acknowledgements}

We are grateful to the financial support for this work from the National Natural Science Foundation of China (21172124), the National Basic Research Science Foundation of China (2010CB126105) for financial support of this research and the National Key Technologies R\&D Program (2011BAE06B05).

Received: 11 July 2012 Accepted: 28 August 2012

Published: 11 September 2012

\section{References}

1. Cetin H, Yanikoglu A, Cilek JE: Larvicidal activity of selected plant hydrodistillate extracts against the house mosquito, Culex pipiens, a West Nile virus vector. Parasitol Res 2011, 108:943-948

2. James AA: Mosquito molecular genetics: the hands that feed bite back. Science 1992, 257(5066):37-38.

3. Begum NA, Roy N, Laskar RA, Roy K: Mosquito larvicidal studies of some chalcone analogues and their derived products: structure-activity relationship analysis. Med Chem Res 2011, 20:184-191.
4. Kannathasan K, Senthilkumar A, Venkatesalu V: Mosquito larvicidal activity of methyl-p-hydroxybenzoate isolated from the leaves of Vitex trifolia Linn. Acta Trop 2011, 120:115-118.

5. Sun R, Li Y, LV M, Xiong L, Wang Q: Synthesis, larvicidal activity, and SAR studies of new benzoylphenylureas containing oxime ether and oxime ester group. Bioorg Med Chem Lett 2010, 20:4693-4699.

6. Talontsi FM, Matasyoh JC, Ngoumfo RM, Chepkorir R: Mosquito larvicidal activity of alkaloids from Zanthoxylum lemairei against the malaria vector Anopheles gambiae. Pest Biochem Physiol 2011, 99:82-85.

7. Yang YC, Lee SG, Lee HK, Kim MK, Lee SH, Lee HS: A piperidine amide extracted from Piper Longum L. fruit shows activity against Ades aegypti mosquito larvae. J Agric Food Chem 2002, 50:3765-3767.

8. Wu J, Wang J, Hu DY, He M, Jin LH, Song BA: Synthesis and antifungal activity of novel pyrazolecarboxamide derivatives containing a hydrazone moiety. Chem Cent J 2012, 6:51.

9. Liu XH, Tan CX, Weng JQ: Phase transfer catalyzed one pot synthesis and biological activity of some novel $\mathrm{N}$ - Pyrimidinyl - $\mathrm{N}^{\prime}$ - nicotinyl thiourea derivatives. Phosphorus Sulfur Silicon Relat Elem 2011, 186:552-557.

10. Liu XH, Tan CX, Weng JQ: Microwave synthesis and biological activity of hydrazone derivatives containing 1,2,3-thiadiazole. Asian J Chem 2011, 23:4064-4066

11. Su NN, Li Y, Yu SJ, Zhang X, Liu XH, Zhao WG: Microwave-assisted synthesis of some novel 1,2,3-triazoles by click chemistry, and their biological activity. Res Chem Intermed 2012. doi:10.1007/s11164-012-0595-9.

12. Xue $Y L$, Zhang YG, Liu XH: Synthesis, crystal structure and biological activity of 1-Cyano-N-(2,4-dichlorophenyl)cyclopropanecarboxamide. Asian J Chem 2012, 24:5087-5089.

13. Liu XH, Pan L, Ma Y, Weng JQ, Tan CX, Li YH, Shi YX, Li BJ, Li ZM, Zhang YG: Design, Synthesis, Biological Activities, and 3D-QSAR of New N, N'Diacylhydrazines Containing 2-(2,4-dichlorophenoxy)propane Moiety. Chem Biol Drug Des 2011, 78:689-694.

14. Xue YL, Liu XH, Zhang YG: Synthesis, crystal structure and biological activity of 1-Cyano-N-(4-bromophenyl)cyclopropanecarboxamide. Asian J Chem 2012, 24:3016-3018.

15. Xue YL, Liu XH, Zhang YG: Synthesis, crystal structure and biological activity of 1-Cyano-N-phenyl-cyclopropanecarboxamide. Asian J Chem 2012, 24:1571-1574

16. Wu J, Yang S, Song BA, Bhadury PS, Hu DY, Zeng S, Xie HP: Synthesis and insecticidal activities of novel neonicotinoid analogs bearing an amide moiety. J Heterocycl Chem 2011, 48:901-906.

17. Xiao YM, Yang XL, Li B, Yuan HZ, Wan SQ, Xu YJ, Qin ZH: Design, synthesis and antifungal/insecticidal evaluation of novel cinnamide derivatives. Molecules 2011, 16:8945-8957.

18. Karolyi Bl, Bosze S, Orban E, Sohar P, Drahos L, Gal E, Csampai A: Acylated mono-, bis- and tris- cinchona-based amines containing ferrocene or organic residues: synthesis, structure and in vitro antitumor activity on selected human cancer cell lines. Molecules 2012, 17:2316-2329.

19. Chhikara BS, Jean NS, Mandal D, Kumar A, Parang K: Fatty acyl amide derivatives of doxorubicin: Synthesis and in vitro anticancer activities. Eur J Med Chem 2011, 46:2037-2042.

20. Wu J, Kang S, Song B, Hu D, He M, Jin L, Yang S: Synthesis and antibacterial activity against ralstonia solanacearum for novel hydrazone derivatives containing a pyridine moiety. Chem Cent J 2012, 6:28.

21. Munday RH, Denton RM, Anderson JC: Asymmetric synthesis of 6'-hydroxyarenarol: the proposed biosynthetic precursor to popolohuanone E. J Org Chem 2008, 73:8033-8038.

22. Zhou H, Meng XJ, LV J, Yi P, Zheng J: Synthesis of 3-methoxy-4hydroxyphenylacetic acid. Chem Reagent 1998, 20:314-314.

23. Zhao Y: The synthesis of 3-methoxy-4-hydroxymandelic acid. J Chengde Pet Coll 2000, 2:31-34.

24. Herbert EF, Harold H: Studies on lignin and related compounds. LXXXIII. Synthesis of 3-Hydroy-1-(4-hydroxy-3-methoxyphenyl)-2-propanone. J Am Chem Soc 1947, 69:1208-1210.

25. Kuchař M, Brůnová B, Rejholec V, Grimová J, Němeček O: Substituted benzyloxyarylacetic acids: synthesis and quantitative relations between structure and antiinflammatory activity. Collect Czech Chem Commun 1977, 42:1723-1735

26. Cong S, Wang T, Shen DL, Sun NB: Synthesis of 4-ethoxybenzeneacetic acid. Fine Chem Intermed 2006, 36:32-34. 47 
27. Barger G, Eisenbrand J, Eisenbrand L, Schlittler E: Constitution of laurotetanine. Berichte der Deutschen Chemischen Gesellschaft B: Abhandlungen 1933, 66B:450-461.

28. Shepard ER, Porter HD, Noth JF, Simmans CK: Preparation of some analogs of papaverine. J Org Chem 1952, 17:568-576.

29. Buu-Hoi NP, Lambelin G, Gillet C: Antiinflammatory substituted phenylacetic acids; 1969. GB1174535.

30. Sheldrick GM: SHELXS97 and SHELXL97. Germany: University of Göttingen; 1997.

\section{doi:10.1186/1752-153X-6-99}

Cite this article as: Wu et al: Synthesis, crystal structure and larvicidal activity of novel diamide derivatives against Culex pipiens. Chemistry

Central Journal 2012 6:99.

\section{Publish with ChemistryCentral and every scientist can read your work free of charge \\ "Open access provides opportunities to our colleagues in other parts of the globe, by allowing anyone to view the content free of charge." \\ W. Jeffery Hurst, The Hershey Company. \\ - available free of charge to the entire scientific community \\ - peer reviewed and published immediately upon acceptance \\ - cited in PubMed and archived on PubMed Central \\ - yours - you keep the copyright

